\title{
Mannan-Modified PLGA Nanoparticles for Targeted Gene Delivery
}

\author{
Fansheng Kong, Linfu Ge, Ximin Liu, Ning Huang, and Fang Zhou \\ Department of Hematology, General Hospital of Ji'nan Command, PLA, 25 Shifan Road, Ji'nan 250031, China \\ Correspondence should be addressed to Fang Zhou, zhoufangphd@yahoo.com.cn
}

Received 28 April 2011; Revised 28 May 2011; Accepted 15 June 2011

Academic Editor: Rodica-Mariana Ion

Copyright ( $\odot 2012$ Fansheng Kong et al. This is an open access article distributed under the Creative Commons Attribution License, which permits unrestricted use, distribution, and reproduction in any medium, provided the original work is properly cited.

\begin{abstract}
The studies of targeted gene delivery nanocarriers have gained increasing attention during the past decades. In this study, mannan modified DNA loaded bioadhesive PLGA nanoparticles (MAN-DNA-NPs) were investigated for targeted gene delivery to the Kupffer cells (KCs). Bioadhesive PLGA nanoparticles were prepared and subsequently bound with $p E G F P$. Following the coupling of the mannan-based PE-grafted ligands (MAN-PE) with the DNA-NPs, the MAN-DNA-NPs were delivered intravenously to rats. The transfection efficiency was determined from the isolated KCs and flow cytometry was applied for the quantitation of gene expression after $48 \mathrm{~h}$ post transfection. The size of the MAN-DNA-NPs was found to be around $190 \mathrm{~nm}$ and the Zeta potential was determined to be $-15.46 \mathrm{mV}$. The pEGFP binding capacity of MAN-DNA-NPs was $(88.9 \pm 5.8) \%$ and the in vitro release profiles of the MAN-DNA-NPs follow the Higuchi model. When compared with non-modified DNA-NPs and Lipofectamine 2000-DNA, MAN-DNA-NPs produced the highest gene expressions, especially in vivo. The in vivo data from flow cytometry analysis showed that MAN-DNA-NPs displayed a remarkably higher transfection efficiency (39\%) than non-modified DNA-NPs (25\%) and Lipofectamine 2000-DNA (23\%) in KCs. The results illustrate that MAN-DNA-NPs have the ability to target liver KCs and could function as promising active targeting drug delivery vectors.
\end{abstract}

\section{Introduction}

Biodegradable nanoparticles have been used frequently as gene delivery vehicles due to their extensive bioavailability, better encapsulation, high stability, and minimal toxicity [1]. They can be tailor made to achieve both controlled drug release and tumor targeting by tuning the polymer characteristics and shaping the surface through nanoengineering [2]. A number of different polymers, both synthetic and natural, have been utilized in formulating biodegradable nanoparticles [3-5]. One of the most extensively investigated polymers for nanoparticles is the biodegradable and biocompatible poly(D,L-lactide-co-glycolide) (PLGA), which has been approved by the FDA for certain human clinical uses [6].

Active targeting is a noninvasive approach to transport drugs and genes to target sites with the help of site-specific ligands [7]. Nanocarriers with active targeting properties could potentially be delivered to specific organs, tissues, cells, or even cellular organelles. Various kinds of targeting residues such as antibodies, peptides, and saccharides have been applied towards the modification of nanocarriers to achieve active targeting $[8,9]$. Nanocarriers modified with saccharides, have seen advancement due to their high specificity, low toxicity, and low immunogenicity. Recently, bioadhesive PLGA nanoparticles were established as promising drug delivery systems $[6,10]$, and mannan-based PE-grafted ligands (MAN-PEs) were synthesized and applied for the surface modification of nanocarriers to achieve active targeting [11]. In this study, MAN-PE-modified bioadhesive PLGA nanoparticles were investigated as active targeting gene delivery system using plasmid enhanced green fluorescent protein $(p E G F P)$ as the model gene.

In the present study, MAN-PEs were applied for the surface modification of PLGA nanoparticles to achieve active targeting to the liver. In vitro and in vivo behavior 
of mannan-modified DNA-loaded PLGA nanoparticles was investigated in comparison with nonmodified DNA-loaded PLGA nanoparticles.

\section{Materials and Methods}

2.1. Materials. Poly(d,l-lactic-co-glycolic) (PLGA, 50:50, Av.MW 25,000) was obtained from Shandong Institute of Medical Instrument (China). Mannan and L- $\alpha$-phosphatidylethanolamine (PE) were purchased from SigmaAldrich Co. (USA). pEGFP-N1 was provided by Shandong University (China). PicoGreen reagent and Lipofectamine 2000 were obtained from Invitrogen Corporation (USA). MTT (3-[4,5-dimehyl-2-thiazolyl]-2,5-diphenyl-2Htetrazolium bromide) was purchased from Sigma-Aldrich (China). All other chemicals were of analytical grade or higher.

2.2. Animals. Adult male Sprague-Dawley rats (10-to-15week old) were purchased from the Medical Animal Test Center of Shandong Province and housed under standard laboratory conditions. All animal experiments complied with the requirements of the National Act on the Use of Experimental Animals (People's Republic of China).

2.3. Preparation of Bioadhesive PLGA Nanoparticles. Bioadhesive PLGA nanoparticles (NPs) were prepared following the methods described by Zou et al. [6, 10]. Carbopol 940 (CP) was dispersed in distilled water at room temperature and left overnight to swell. Neutralization of the CP dispersion was achieved by adding the required amount of $1 \mathrm{M}$ $\mathrm{NaOH}$ until pH 7.0 was reached. The resulting $\mathrm{CP}$ stock solution was diluted with distilled water to afford a $0.02 \%$ (w/v) CP solution. Bioadhesive PLGA nanoparticles were prepared under optimized conditions by a nanoprecipitation method (solvent displacement technique) $[12,13] .50 \mathrm{mg}$ of PLGA polymer was accurately weighted and dissolved in $3 \mathrm{~mL}$ acetone. The organic phase was added dropwise into the $0.02 \% \mathrm{CP}$ solution being stirred at $600 \mathrm{rpm}$ and room temperature. When complete evaporation of the organic solvent had occurred, the redundant stabilizers and the nanoparticles were separated by ultracentrifugation at $1000 \mathrm{~g}, 4^{\circ} \mathrm{C}$ for $20 \mathrm{~min}$. The pellet was resuspended in Milli$\mathrm{Q}$ water, washed three times, and filtered through a $0.45 \mu \mathrm{m}$ membrane. The resulting nanoparticle suspensions were stored at $4^{\circ} \mathrm{C}$ until use.

2.4. Fabrication of DNA-Loaded Nanoparticles. The reporter gene $p E G F P$ was mixed with the PLGA nanoparticles by vortexing the nanoparticle suspension with a $1 \mathrm{mg} / \mathrm{mL}$ solution of DNA for $20 \mathrm{~s}$. Incubation of the mixture for $30 \mathrm{~min}$ at RT facilitated the formation of the DNA-loaded PLGA nanoparticles (DNA-NPs).

2.5. Surface Modification of DNA-Nps with Mannan-PE. Mannan-PE was synthesized in accordance with the method described by Yu et al. [11]. Surface modification of DNA-NPs with mannan-PE ligands was accomplished according to the procedure developed by Vyas et al. [14]. Mannan-PE ligands were dissolved in $5 \mathrm{~mL}$ of phosphate buffered saline (PBS, $\mathrm{pH}$ 7.4). Then, the solution was added at dropwise into $10 \mathrm{~mL}$ of DNA-NPs that were stirred at $800 \mathrm{rpm}$ by a laboratory magnetic stirrer at RT. The suspension was continually stirred at $600 \mathrm{rpm}$ until the completion of modification. The excessive nonmodified ligands were removed by spinning the resultant suspension through a Sephadex G-50 column at $2,000 \mathrm{rpm}$ for $5 \mathrm{~min}$. The pellet was resuspended in MilliQ water, washed three times, and filtered through a $0.80 \mu \mathrm{m}$ membrane to obtain the desired mannan-modified DNAloaded PLGA nanoparticles (MAN-DNA-NPs).

As a result of the modification process, the hydrophobic PE domains coated the surface of bioadhesive DNA-NPs, masking the inherent charge on the carriers. The total ligandto-carrier weight ratio was optimized by measuring the change in Zeta potential. The optimum ratio was found to occur when increasing the ligand-to-carrier weight ratio resulted in no significant change in Zeta potential.

2.6. Characterization of MAN-DNA-NPs and DNA-NPs. The surface morphologies of both the MAN-DNA-NPs and the nonmodified DNA-NPs were examined by transmission electronic microscopy (TEM). The mean particle size and Zeta potential of the NPs were analyzed by photon correlation spectroscopy (PCS) and laser Doppler anemometry, respectively.

PicoGreen-fluorometry assay was carried out to measure the adsorption efficiency of the DNA loaded NPs $[9,15]$. The pEGFP was isolated from the MAN-DNA-NPs and DNANPs by centrifugation at $1000 \mathrm{~g}, 4^{\circ} \mathrm{C}$ for $20 \mathrm{~min}$. Analysis of the $p E G F P$ containing supernatants by a fluorescence spectrophotometer afforded the concentration of plasmid DNA.

2.7. In Vitro DNA Release Studies. The MAN-DNA-NPs and DNA-NPs were placed in phosphate buffered solution (PBS, pH 7.4) to characterize the DNA release profile [16]. Typically, aliquots of complexes (equivalent to $1 \mu \mathrm{g}$ DNA) were suspended in Eppendorf tubes containing $1 \mathrm{~mL}$ of PBS and vortexed. The tubes were continuously shaken in a $37^{\circ} \mathrm{C}$ water bath at $100 \mathrm{rpm}$. Separate tubes were used for each data point. At predetermined time intervals, the nanoparticle suspensions were centrifuged $\left(1000 \mathrm{~g}, 4^{\circ} \mathrm{C}\right.$ for $20 \mathrm{~min}$ ) and the amount of DNA released in the supernatant was analyzed by the PicoGreen assay mentioned above. Background readings were obtained using the supernatants from the blank PLGA-NPs.

2.8. Isolation and Culture of Kupffer Cells. Kupffer cells (KCs) were isolated from SD rats under pentobarbitone anaesthesia [17-20]. The rats' portal vein were cannulated and perfused with HBSS for 10 min at RT. During this time, the liver was excised and the perfusate discarded. The liver was then perfused with $0.2 \%$ pronase $(60 \mathrm{~mL}$ at RT) which was discarded. Then, the liver was perfused with a recirculating solution of $0.05 \%$ pronase and $0.05 \%$ collagenase $(60 \mathrm{~mL}$ at $\mathrm{RT})$ until the liver was digested as judged by the softening of the liver parenchyma beneath the capsule. The liver was then cut into 
small pieces, suspended in $100 \mathrm{~mL}$ solution containing $0.02 \%$ pronase, $0.05 \%$ collagenase, and $0.005 \%$ DNase, and agitated at RT for $20 \mathrm{~min}$. Following digestion, the liver homogenate was filtered through sterile gauze and centrifuged (1000 g, $4^{\circ} \mathrm{C}$ for $10 \mathrm{~min}$ ). The supernatant was removed and the pellet resuspended in $10 \mathrm{~mL}$ Percoll gradient. Aliquots $(5 \mathrm{~mL})$ of this cell suspension were added to $5 \mathrm{~mL}$ aliquots of Percoll gradient. These were carefully overlaid with $5 \mathrm{~mL}$ HBSS and centrifuged at $1000 \mathrm{~g}, 4^{\circ} \mathrm{C}$ for $20 \mathrm{~min}$. The nonparenchymal cell-enriched layer observed at the interface between the two layers was carefully harvested and diluted with $10 \mathrm{~mL}$ of HBSS. The suspension was then centrifuged $\left(1000 \mathrm{~g}, 4^{\circ} \mathrm{C}\right.$ for $20 \mathrm{~min}$ ) to precipitate the KCs, which were then seeded into a 96-well microtiter plate at a density of $2 \times 10^{4}$ cells/well in $200 \mu \mathrm{L}$ RPMI 1640 supplemented with $10 \%$ fetal bovine serum (FBS) and antibiotics. After incubation at $37^{\circ} \mathrm{C}$ for $2 \mathrm{~h}$ under $5 \% \mathrm{CO}_{2}$ atmosphere, the culture medium was replaced by $200 \mu \mathrm{L}$ fresh RPMI 1640 to yield the purified KCs.

\subsection{In Vitro Cytotoxicity Evaluation and Transfection Analysis.} The in vitro cytotoxicity of MAN-NPs was evaluated by MTT assay [21] in the above cultured KCs. After incubation at $37^{\circ} \mathrm{C}$ for $24 \mathrm{~h}$ under $5 \% \mathrm{CO}_{2}$ atmosphere, the culture medium was replaced with $200 \mu \mathrm{L}$ of fresh RPMI 1640 containing various concentrations of the MAN-NPs or Lipofectamine 2000 for comparison, and the cells were incubated for another $24 \mathrm{~h}$. The cell viability was then assessed by MTT assay. $5 \mathrm{mg} / \mathrm{mL}$ of MTT in PBS was then added to each well, and the plate was incubated for an additional $4 \mathrm{~h}$ at $37^{\circ} \mathrm{C}$ under the aforementioned $5 \% \mathrm{CO}_{2}$ atmosphere. Then, the MTT containing medium was removed, and the crystals formed by living cells were dissolved in $100 \mu \mathrm{L}$ DMSO. The absorbance at $570 \mathrm{~nm}$ was determined by a microplate reader. Untreated cells were taken as a control with $100 \%$ viability, and cells without the addition of MTT were used as a blank to calibrate the spectrophotometer to zero absorbance. The relative cell viability (\%) compared to control cells was calculated using $\left(\mathrm{Abs}_{\text {sample }} / \mathrm{Abs}_{\text {control }}\right) \times 100$.

For transfection efficiency analysis, the KCs were seeded into 24 -well plates at a density of $1 \times 10^{5}$ cells/well in $1 \mathrm{~mL}$ of RPMI-1640 with $10 \%$ FBS, $24 \mathrm{~h}$ prior to transfection. When the cells were at about $80 \%$ confluence, the media was replaced with $200 \mu \mathrm{L}$ serum-free media containing MANDNA-NPs and DNA-NPs. Naked DNA was used as a negative control. Lipofectamine 2000 was used as a positive control. The original incubation medium was replaced with $1 \mathrm{~mL}$ of complete medium after incubation at $37^{\circ} \mathrm{C}$ for $4 \mathrm{~h}$ under a $5 \% \mathrm{CO}_{2}$ atmosphere. The cells were incubated and were studied every $12 \mathrm{~h}$ until $48 \mathrm{~h}$ after transfection. The fluorescent cells were observed using an inversion fluorescence microscope, at which time pictures were taken for the record.

2.10. In Vivo Delivery and Transfection. Adult male SpragueDawley rats (10-to-15-week old) were divided into five groups (six rats in each group) and injected intravenously with $1 \mathrm{~mL}$ of both MAN-DNA-NPs and DNA-NPs. Identical intravenous doses of blank NPs, naked $P E G F P$, and Lipofectamine 2000-DNA served as controls. At predetermined time
TABle 1: Particle size and Zeta potential of NPs, DNA-NPs, and MAN-DNA-NPs (mean $\pm \mathrm{SD}, n=3$ ).

\begin{tabular}{lccc}
\hline Sample & $\begin{array}{c}\text { Mean particle } \\
\text { size }(\mathrm{nm})\end{array}$ & $\begin{array}{c}\text { Polydispersity } \\
\text { index }(\mathrm{PDI})\end{array}$ & $\begin{array}{c}\text { Zeta potential } \\
(\mathrm{mV})\end{array}$ \\
\hline NPs & $116.7 \pm 3.2$ & $0.19 \pm 0.05$ & $-29.18 \pm 3.54$ \\
DNA-NPs & $145.3 \pm 8.7$ & $0.23 \pm 0.08$ & $-36.58 \pm 1.32$ \\
MAN-DNA-NPs & $189.7 \pm 5.3$ & $0.15 \pm 0.07$ & $-15.46 \pm 1.09$ \\
\hline
\end{tabular}

intervals, the rats' KCs were isolated under pentobarbitone anaesthesia as described in Section 2.8. The KCs were then seeded into 24-well plates in $1 \mathrm{~mL}$ of RPMI 1640 with $10 \%$ FBS. The fluorescent cells were observed using an inversion fluorescence microscope, and the pictures were captured.

For further quantitation of the transfection efficiency, flow cytometry was used. Cells were washed with $1 \mathrm{~mL}$ of PBS $\left(100 \mathrm{~g}, 4^{\circ} \mathrm{C}\right.$ for $\left.5 \mathrm{~min}\right)$ and were detached with trypsin/EDTA. The supernatant was discarded and resuspended with $300 \mu \mathrm{L}$ of PBS, mixed well, and added into the flow cytometer to determine the amount of KCs which has been successfully transfected.

2.11. Statistical Analysis. All studies were repeated a minimum of three times and all measurements were carried out in triplicate. Results were reported as means \pm SD (SD = standard deviation). Statistical significance was analyzed using the Student's $t$-test. Differences between experimental groups were considered significant when the $P$ value was less than $0.05(P<0.05)$.

\section{Results}

3.1. Characterization of DNA Loaded NPs. The transmission electron micrograph (TEM) pictures of the MAN-DNANPs and DNA-NPs were shown in Figure 1. DNA-NPs had spherical shapes (Figure 1(a)) while the MAN-DNA-NPs had dark coats on the white particles (Figure 1(b)). Mean particle size, polydispersity index (PDI), Zeta potential of blank PLGA nanoparticles (NPs), DNA-NPs, and MAN-DNA-NPs were characterized and summarized in Table 1.

To optimize the mannan-PE to DNA-NPs weight ratio, the change in Zeta potential was measured and the optimum ratio was obtained when no significant change in Zeta potential was observed after increasing the mannan-PE percent. The optimum ratio was obtained at $1 / 2$ (mannanPE/DNA-NPs, w/w) (Figure 2).

3.2. Gene Loading Capacity and In Vitro Release Studies. PicoGreen fluorometry assay was carried out to quantitate the loading efficiencies of the gene delivery systems. DNA binding quantity $(\%)=($ total amount of DNA - the amount of free DNA)/total amount of DNA $\times 100$. The $p E G F P$ binding capacities of MAN-DNA-NPs and DNA-NPs were $(88.9 \pm 5.8) \%$ and $(89.5 \pm 4.5) \%$, respectively.

The in vitro release profiles of modified and nonmodified DNA-NPs are illustrated in Figure 3 and the release behavior of the MAN-DNA-NPs and DNA-NPs follow the Higuchi model best. 


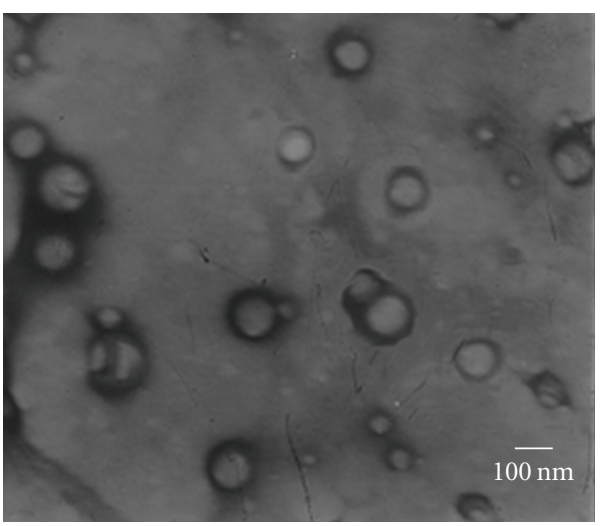

(a)

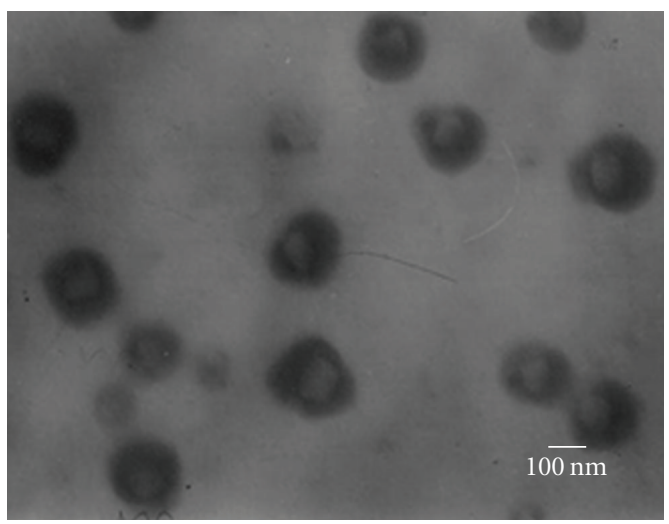

(b)

Figure 1: TEM imaging of DNA-NPs (a) and MAN-DNA-NPs (b).

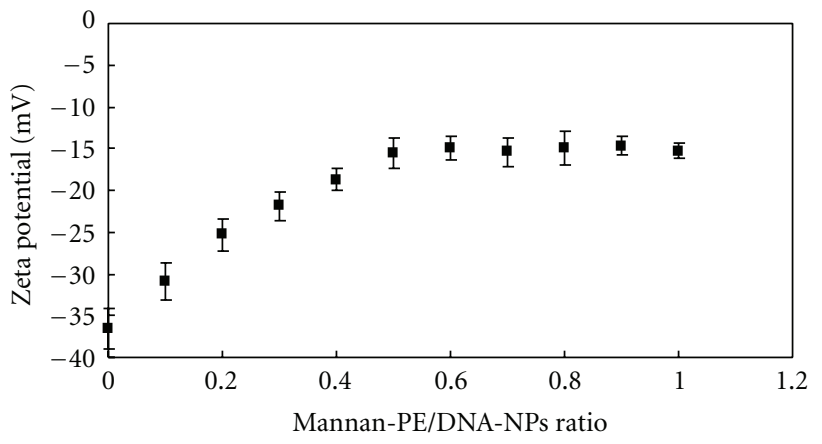

Figure 2: Optimization of mannan-modified DNA-NPs: MAN-PEs to DNA-NPs weight ratio (w/w).

3.3. In Vitro Cytotoxicity and Transfection. The isolated Kupffer cells were defined on the basis of the presence of phagocytosis of latex beads and or positive immunostaining with antibody to the epitope ED2. With the above-mentioned method, about 81 . $52 \times 10^{6} /$ rat liver Kupffer cells were obtained, purity was around $92 \%$ (to $88.69 \times 10^{6} /$ rat liver NPC), and more than $95 \%$ cells were alive. The isolated and purified rat Kupffer cells retained their in vivo morphological, biological and immunological characteristics.

In vitro toxicity of modified and nonmodified NPs was evaluated by MTT assay in rat KCs. The cytotoxicity of

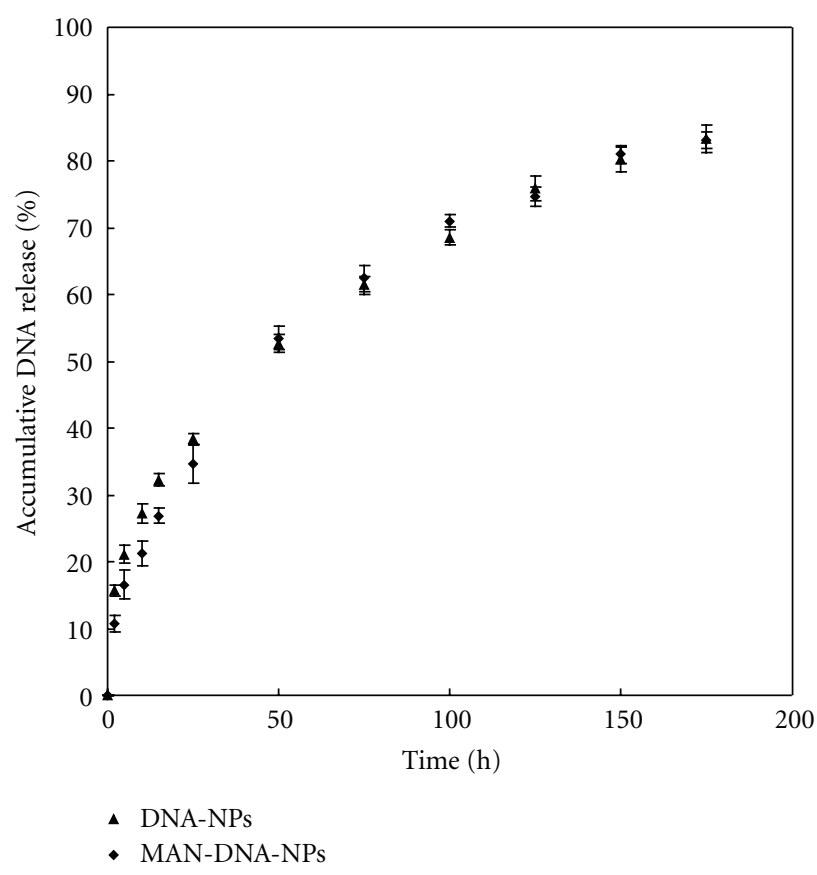

FIGURE 3: In vitro release profile of MAN-DNA-NPs and DNA-NPs (mean $\pm \mathrm{SD}, n=3$ ).

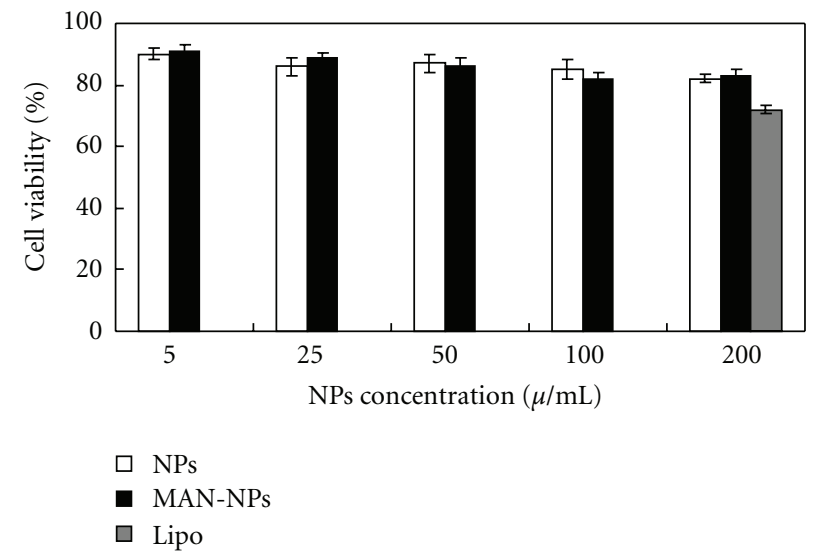

FIgURE 4: Cell viabilities of MAN-DNA-NPs and DNA-NPs (mean $\pm \mathrm{SD}, n=3)$.

MAN-NPs and NPs at various concentrations (5, 25, 50, 100, and $200 \mu \mathrm{g} / \mathrm{mL}$ ) was evaluated. Lipofectamine 2000 at the concentration of transfection was used as comparison. The cell viabilities in the presence of NPs and MAN-NPs over the studied concentration range $(5-200 \mu \mathrm{g} / \mathrm{mL})$ were between 80 and $120 \%$ compared with controls (Figure 4 ). MAN-NPs and NPs exhibited a lower cytotoxicity than Lipofectamine 2000 at all concentrations $(P<0.05)$.

The in vitro transfection efficiencies of MAN-DNANPs and DNA-NPs in KCs after $48 \mathrm{~h}$ of transfection are shown in Figure 5. When compared with naked DNA, DNANPs, and Lipofectamine-DNA, MAN-DNA-NPs had higher transfection efficiency. 


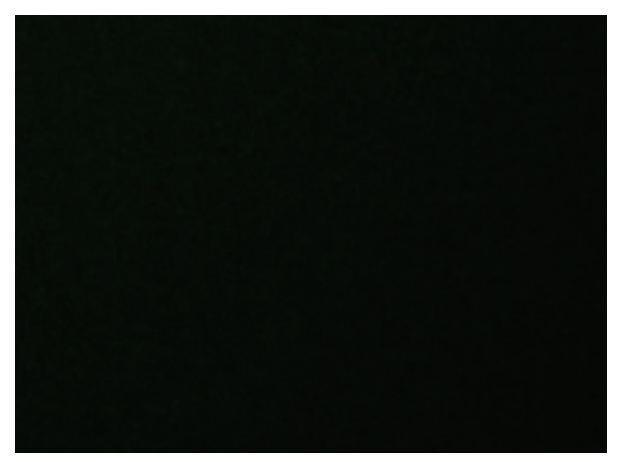

(a)

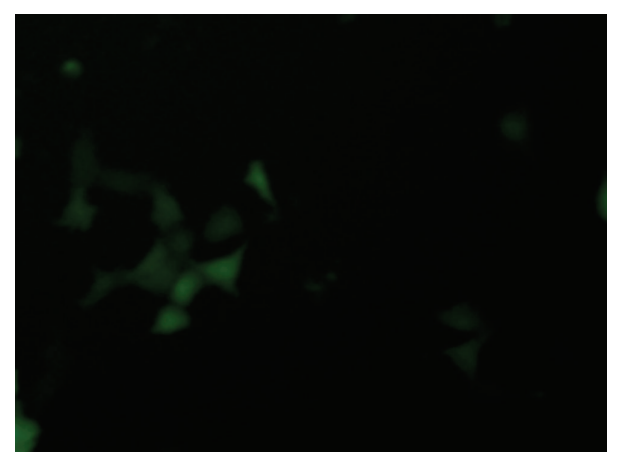

(b)

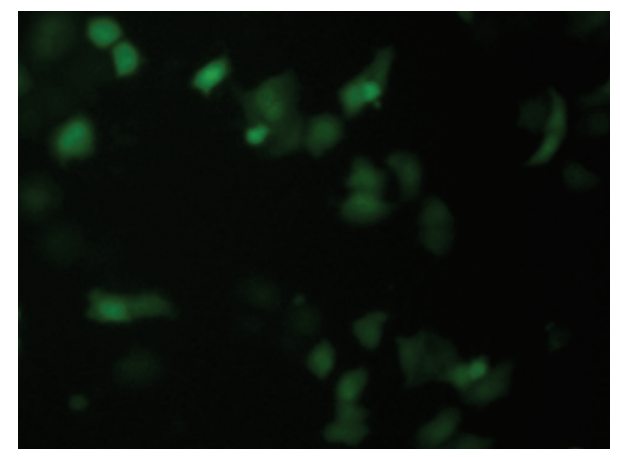

(c)

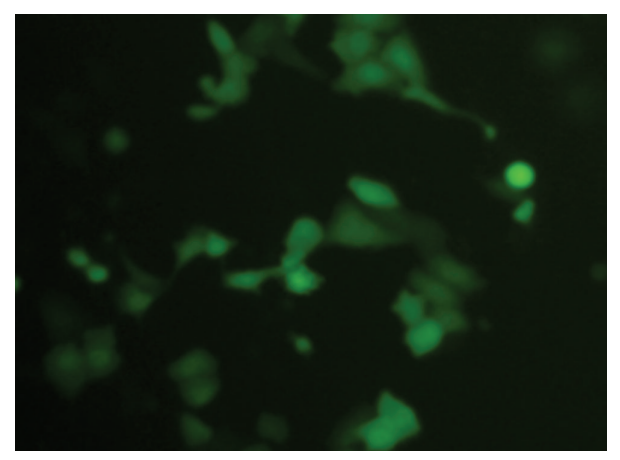

(d)

Figure 5: Fluorescent micrographs of KCs transfected by plasmid EGFP with DNA-NPs (c) and MAN-DNA-NPs (d). The KCs transfected by naked DNA (a), and Lipofectamine-DNA (b) was used as control.
$12 \mathrm{~h}$
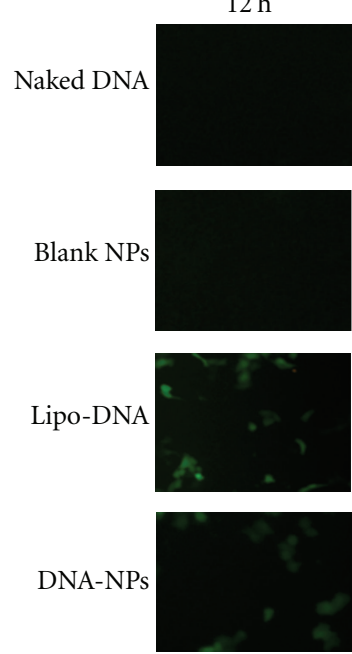

MAN-DNA-NPs
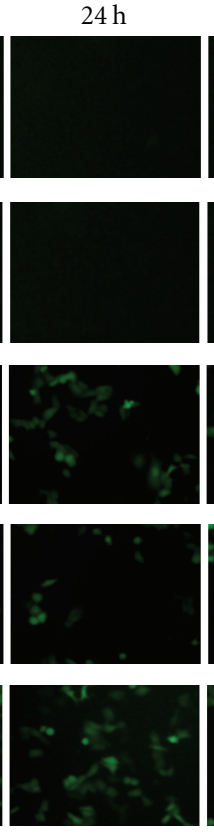

Figure 6: Fluorescent micrographs of KCs transfected by plasmid EGFP in vivo. Gene expression was examined after 12, 24 and $48 \mathrm{~h}$ post injection.

3.4. In Vivo Gene Delivery in Rats. After intravenous injection of naked DNA, blank NPs, Lipofectamine 2000-DNA, DNA-NPs, and MAN-DNA-NPs, the KCs were isolated at $12 \mathrm{~h}, 24 \mathrm{~h}$, and $48 \mathrm{~h}$. The fluorescent cells were observed using an inverted fluorescence microscope (Figure 6). The pictures apparently showed that MAN-DNA-NPs had better transfection efficiency in rats compared with nonmodified DNA-NPs and Lipofectamine 2000-DNA. Flow cytometry was applied for the further quantitation of gene expression after $48 \mathrm{~h}$ following transfection. As shown in Figure 7, the percentage of KCs transfected with $p E G F P$ appeared at the UR and LR quadrants, MAN-DNA-NPs displayed a remarkably higher transfection efficiency than nonmodified DNA-NPs $(P<0.05)$ and Lipofectamine 2000-DNA $(P<$ $0.05)$ in KCs.

\section{Discussion}

In the present study, novel mannan-modified bioadhesive PLGA nanocarriers were constructed as active targeting gene delivery system. As illustrated in Figure 1 and Table 1, nonmodified DNA-NPs had spherical shapes while the mannan-modified MAN-DNA-NPs had a dark coat on the white balls, which may be employed to identify the successful coating of mannan-PE. The mean particle size of NPs was around $100-200 \mathrm{~nm}$, which is ideal for the nanoparticulate system.

During the modification procedure, mannan containing ligands were extensively coated onto the DNA-NPs' surface, which covered their original charge and caused the change in Zeta potential. The optimization of ligand-to-carrier ratio was carried out by measure the Zeta potential. The optimum ratio was obtained at $1 / 2$ (mannan-PE/DNA-NPs, w/w) 


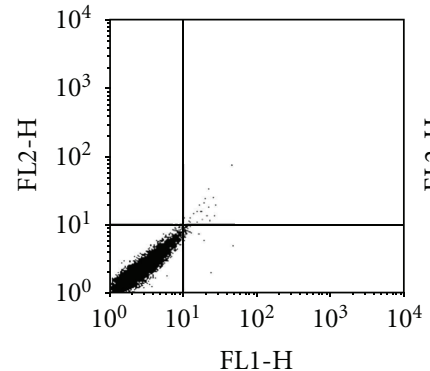

(a)

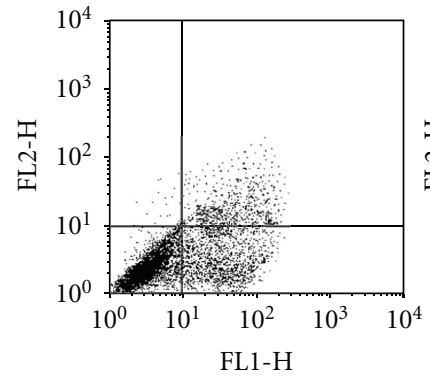

(c)

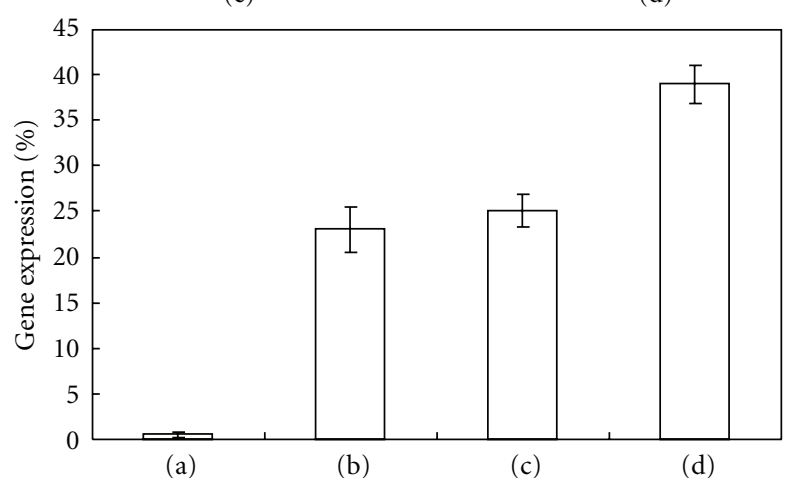

FIGURE 7: Flow cytometry analysis of KCs transfected by plasmid EGFP in vivo. Gene expression was examined after $48 \mathrm{~h}$ following injection. (a) Naked DNA, (b) Lipofectamine-DNA, (c) DNA-NPs, and (d) MAN-DNA-NPs (mean $\pm \mathrm{SD}, n=3$ ).

(Figure 2) and the optimum MAN-DNA-NPs had a Zeta potential of $-15.46 \mathrm{mV}$ (Table 1 ).

PicoGreen fluorometry method was applied to quantitate the loading capacity and in vitro release behavior of MANDNA-NPs. The binding efficiency of MAN-DNA-NPs and DNA-NPs was $88.9 \%$ and $89.5 \%$, which had no significant difference. The results demonstrated that binding of mannan containing ligand onto the NPs surface did not detach the DNA from the complexes. The in vitro release profiles (Figure 3) of MAN-DNA-NPs and DNA-NPs were nearly identical. These findings support the notion that the coating of mannan did not hinder the release of DNA. The release profiles of the MAN-DNA-NPs and DNA-NPs both follow the Higuchi model, MAN-DNA-NPs: $Q \%=0.0654 t^{1 / 2}+$ 0.0206, $r=0.9952$; DNA-NPs: $Q \%=0.063 t^{1 / 2}+0.05848$, $r=0.9958$.

Macrophages play a major role in the immune response to foreign antigens, targeting macrophages is one of the important therapeutic ways to treat genetic metabolic diseases such as Gaucher's disease and human immunodeficiency virus (HIV) infection [22]. KCs are liver-specific resident macrophages that play an integral part in the physiological homeostasis of the liver. Kuppfer cells have significant roles in acute and chronic responses of the liver to bacterial and viral infections, toxic or carcinogenic attack, as well as mediating hepatotoxicity [23]. In this study, rat KCs were isolated and used as model cells for in vitro toxicity and transfection evaluation. For cell viability study, both MANNPs and blank NPs showed lower cytotoxicity compared with Lipofectamine $2000(P<0.05$, Figure 4$)$, most probably due to the better biodegradability and bioavailability. The in vitro transfection of MAN-DNA-NPs and DNA-NPs was carried on KCs (Figure 6). After transfection for 48 h, MANDNA-NPs gained better transfection results than DNA-NPs, which may be explained by the sugar-lectin-mediated active targeting mechanism. The modified $p E G F P$ loaded NPs were bound to the KCs and delivered the DNA into the cells to express EGFP.

The in vivo gene delivery and expression studies were applied in rats. After intravenous injection, the KCs were isolated, cultured, and analyzed with fluorescence microscope and flow cytometer. As shown in Figure 6, MAN-DNA-NPs achieved the best transfection efficacy in every data point. For further quantitation of the fluorescent KCs, flow cytometry was applied and the KCs with green fluorescence appeared at the UR and LR quadrants (Figure 7). The modified MANDNA-NPs showed higher transfection efficiency in rats compared with nonmodified DNA-NPs and Lipofectamine 2000 -DNA $(P<0.05)$ which demonstrates that the mannan modified PLGA NPs had the ability to target liver KCs and could function as promising active targeting drug delivery vectors.

\section{Conclusions}

In conclusion, MAN-PEs-modified pEGFP-loaded bioadhesive PLGA-NPs could be targeted delivered to the liver and successfully transfected the KCs. This may be explained by the sugar-lectin-mediated active targeting mechanism. The results indicate that this kind of modification could be generalized to other kinds of nanocarriers and construct many kinds of active targeting drug delivery systems.

\section{Acknowledgment}

The authors thank Dr. Sebastian Temme (Department of Chemistry, Brandeis University) for language editing of the paper.

\section{References}

[1] A. Kumari, S. K. Yadav, and S. C. Yadav, "Biodegradable polymeric nanoparticles based drug delivery systems," Colloids and Surfaces B, vol. 75, no. 1, pp. 1-18, 2010.

[2] D. B. Shenoy and M. M. Amiji, "Poly(ethylene oxide)modified poly(epsiloncaprolactone) nanoparticles for targeted delivery of tamoxifen in breast cancer," International Journal of Pharmaceutics, vol. 293, no. 1-2, pp. 261-270, 2005. 
[3] S. M. Moghimi, A. C. Hunter, and J. C. Murray, "Longcirculating and target-specific nanoparticles: theory to practice," Pharmacological Reviews, vol. 53, no. 2, pp. 283-318, 2001.

[4] K. S. Soppimath, T. M. Aminabhavi, A. R. Kulkarni, and W. E. Rudzinski, "Biodegradable polymeric nanoparticles as drug delivery devices," Journal of Controlled Release, vol. 70, no. 1-2, pp. 1-20, 2001.

[5] J. Panyam and V. Labhasetwar, "Biodegradable nanoparticles for drug and gene delivery to cells and tissue," Advanced Drug Delivery Reviews, vol. 55, no. 3, pp. 329-347, 2003.

[6] W. Zou, C. Liu, Z. Chen, and N. Zhang, "Studies on bioadhesive PLGA nanoparticles: a promising gene delivery system for efficient gene therapy to lung cancer," International Journal of Pharmaceutics, vol. 370, no. 1-2, pp. 187-195, 2009.

[7] A. Beduneau, P. Saulnier, and J. P. Benoit, "Active targeting of brain tumors using nanocarriers," Biomaterials, vol. 28, no. 33, pp. 4947-4967, 2007.

[8] W. Y. Yu and N. Zhang, "Surface modification of nanocarriers for cancer therapy," Current Nanoscience, vol. 5, no. 2, pp. 123134, 2009.

[9] W. Yu, N. Zhang, and C. Li, "Saccharide modified pharmaceutical nanocarriers for targeted drug and gene delivery," Current Pharmaceutical Design, vol. 15, no. 32, pp. 3826-3836, 2009.

[10] W. Zou, G. Cao, Y. Xi, and N. Zhang, "New approach for local delivery of rapamycin by bioadhesive PLGA-carbopol nanoparticles," Drug Delivery, vol. 16, no. 1, pp. 15-23, 2009.

[11] W. Yu, C. Liu, Y. Liu, N. Zhang, and W. Xu, "Mannanmodified solid lipid nanoparticles for targeted gene delivery to alveolar macrophages," Pharmaceutical Research, vol. 27, no. 8, pp. 1584-1596, 2010.

[12] H. Fessi, F. Piusieux, J. P. Devissaguet, N. Ammoury, and S. Benita, "Nanocapsule formation by interfacial polymer deposition following solvent displacement," International Journal of Pharmaceutics, vol. 55, no. 1, pp. R1-R4, 1989.

[13] U. Bilati, E. All'emann, and E. Doelker, "Development of a nanoprecipitation method intended for the entrapment of hydrophilic drugs into nanoparticles," European Journal of Pharmaceutical Sciences, vol. 24, no. 1, pp. 67-75, 2005.

[14] S. P. Vyas, V. Sihorkar, and S. Jain, "Mannosylated liposomes for bio-film targeting," International Journal of Pharmaceutics, vol. 330, no. 1-2, pp. 6-13, 2007.

[15] S. J. Ahn, J. Costa, and J. R. Emanuel, "PicoGreen quantitation of DNA: effective evaluation of samples pre- or post-PCR," Nucleic Acids Research, vol. 24, no. 16, pp. 2623-2635, 1996.

[16] J. Ye, A. Wang, C. Liu, Z. Chen, and N. Zhang, "Anionic solid lipid nanoparticles supported on protamine/DNA complexes," Nanotechnology, vol. 19, no. 28, Article ID 285708, 2008.

[17] J. K. Olynyk and S. L. Clarke, "Isolation and primary culture of rat Kupffer cells," Journal of Gastroenterology and Hepatology, vol. 13, no. 8, pp. 842-845, 1998.

[18] H. Liu, H. Cao, and Z. Y. Wu, "Isolation of Kupffer cells and their suppressive effects on T lymphocyte growth in rat orthotopic liver transplantation," World Journal of Gastroenterology, vol. 13, no. 22, pp. 3133-3136, 2007.

[19] Z. Zeng, H. Huang, F. Song, and J. Duan, "Isolation of rat Kupffer cells by ex vivo perfusion and their primary culture," Shijie Huaren Xiaohua Zazhi, vol. 17, pp. 2550-2554, 2009.

[20] F. Liu, J. Y. Zhu, T. Li, and X. S. Leng, "Improving the ways to isolate, cultivate and identify rat Kupffer cells," Zhonghua Gan Zang Bing Za Zhi, vol. 14, no. 7, pp. 532-535, 2006.

[21] Y. Gao, W. Gu, L. Chen, Z. Xu, and Y. Li, "A multifunctional nano device as non-viral vector for gene delivery: in vitro characteristics and transfection," Journal of Controlled Release, vol. 118, no. 3, pp. 381-388, 2007.

[22] M. Yamada, M. Nishikawa, S. Kawakami et al., "Tissue and intrahepatic distribution and subcellular localization of a mannosylated lipoplex after intravenous administration in mice," Journal of Controlled Release, vol. 98, no. 1, pp. 157-167, 2004.

[23] H. Kitani, T. Takenouchi, M. Sato, M. Yoshioka, and N. Yamanaka, "A novel isolation method for macrophage-like cells from mixed primary cultures of adult rat liver cells," Journal of Immunological Methods, vol. 360, no. 1-2, pp. 4755,2010 


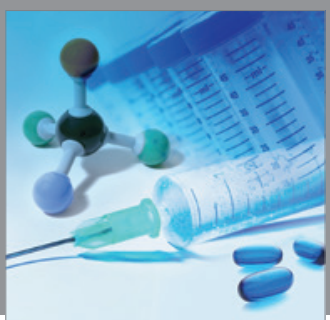

International Journal of

Medicinal Chemistry

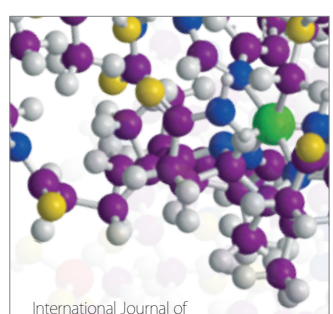

Carbohydrate Chemistry

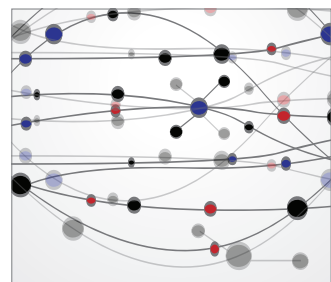

The Scientific World Journal
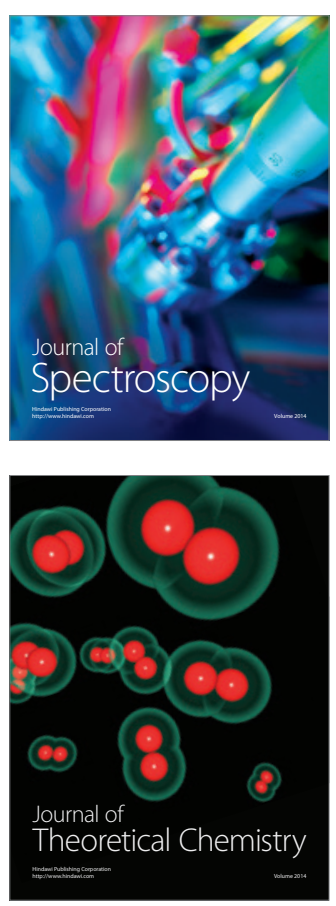
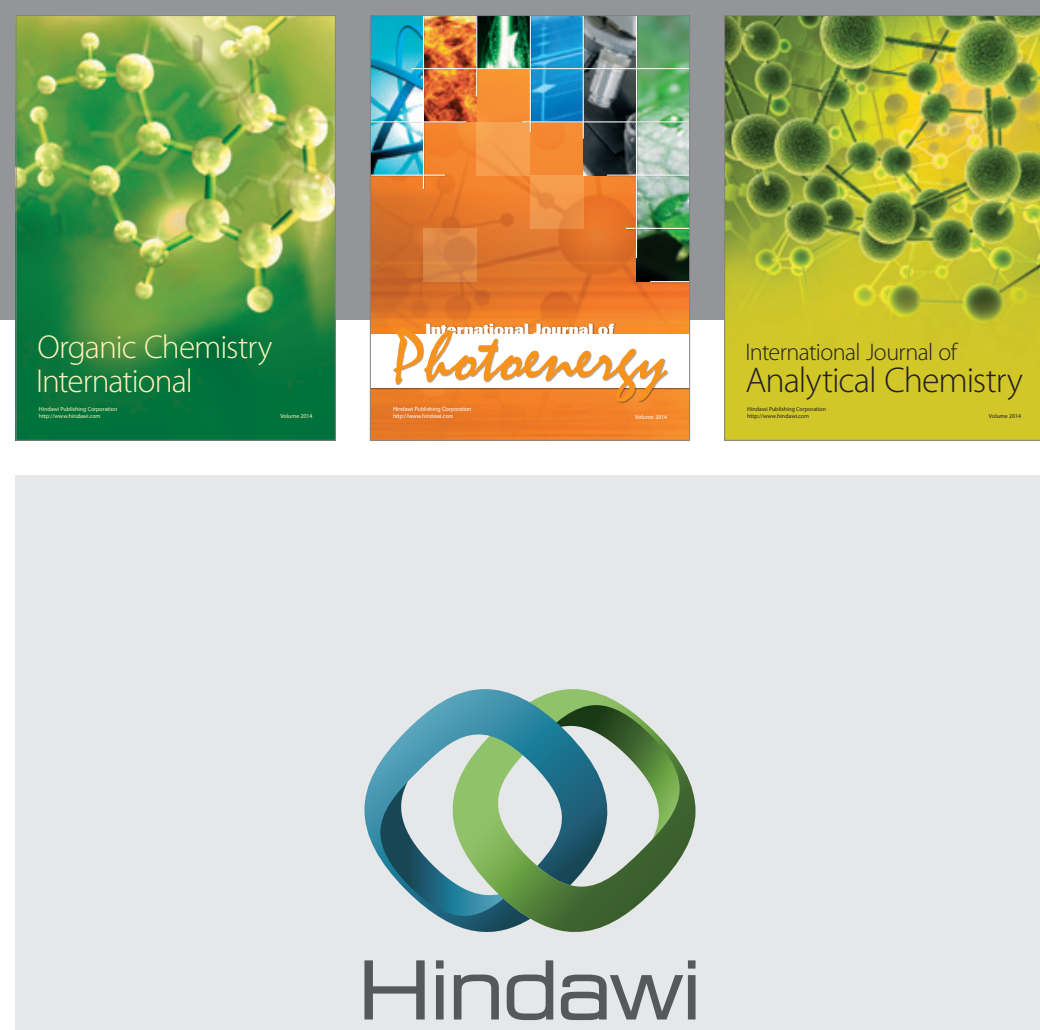

Submit your manuscripts at

http://www.hindawi.com
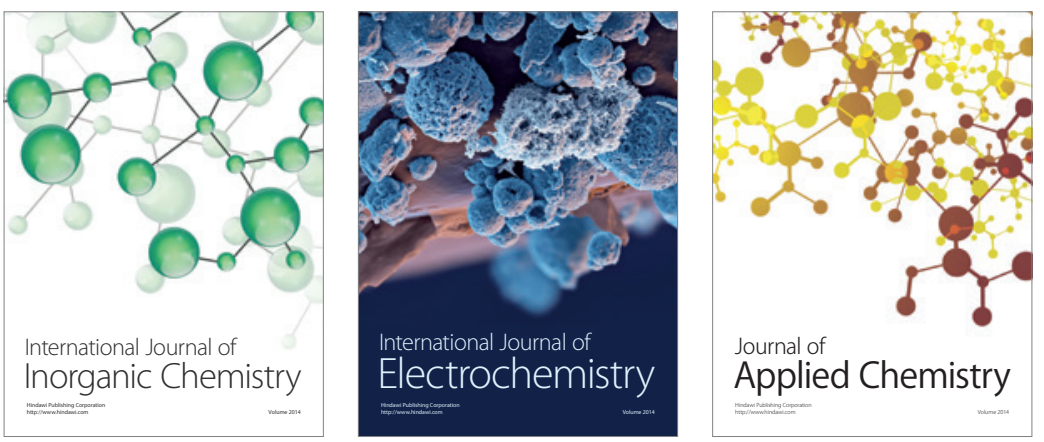

Journal of

Applied Chemistry
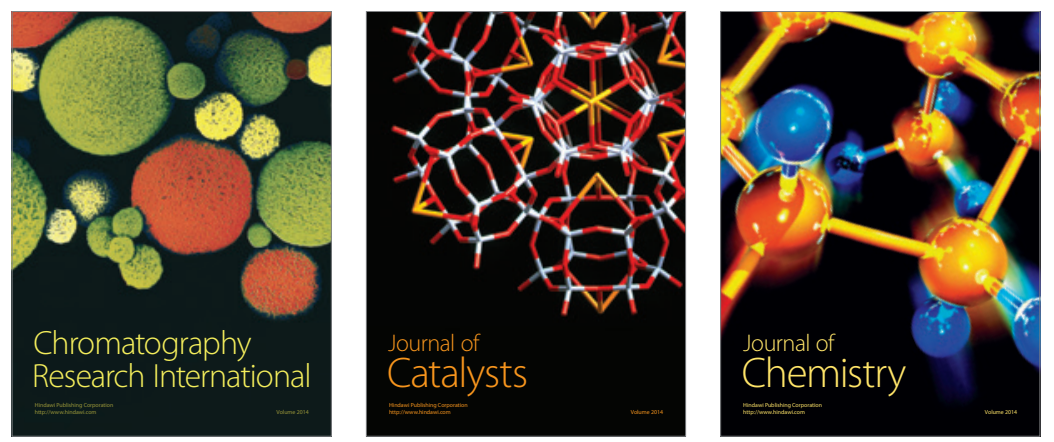
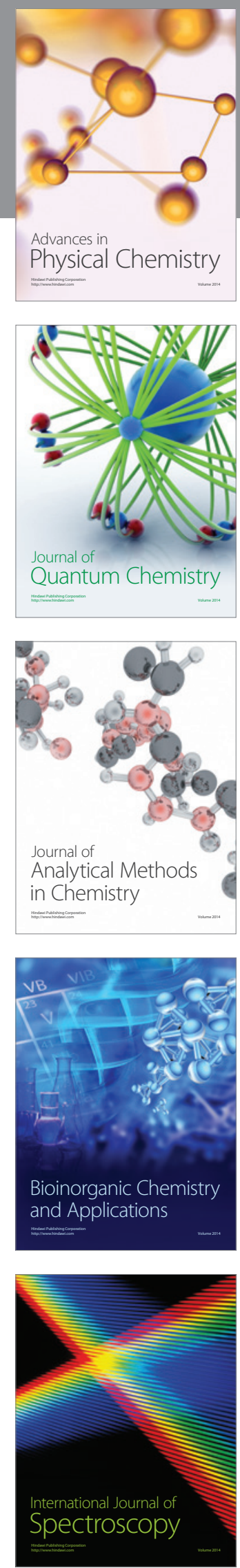